\title{
Stage IV Adult Diffuse Mixed Cell Lymphoma
}

National Cancer Institute

\section{Source}

National Cancer Institute. Stage IV Adult Diffuse Mixed Cell Lymphoma. NCI Thesaurus.

Code C8147.

Stage IV: Disseminated (multifocal) involvement of one or more extralymphatic sites with or without associated lymph node involvement or isolated extralymphatic organ involvement with distant (nonregional) nodal involvement. (PDQ) 